\title{
Banken combineren rendement en risico in RAROC
}

René Doff en Alice van den Tillaart

SAMENVATTING Risicomanagement bij banken staat meer dan ooit in de belangstelling door enkele opzienbarende incidenten en door het recentelijk definitief geworden Bazel II Akkoord. Beide ontwikkelingen hebben een grote invloed op het vakgebied risicomanagement bij banken. Dit artikel beschrijft de wijze waarop banken risico meten en beheersen met behulp van de methodieken economic capital en Risk-Adjusted Return-onCapital (RAROC). Deze methodiek ligt in het verlengde van de vernieuwde Bazel II regelgeving en zal de komende jaren steeds belangrijker worden voor de bancaire besturing. De auteurs beschrijven de methodes in hoofdlijnen en benadrukken het belang van kwalitatieve informatie over risico's. Het concept RAROC zal sterker aan kracht winnen als ook deze informatie een plaats krijgt dan bij verdere verfijning van statistische methoden en historische data.

\section{Inleiding}

Risicomanagement bij banken staat meer dan ooit in de belangstelling. Enerzijds wordt dat veroorzaakt door enkele incidenten die breed werden uitgemeten in de media, zoals Barings in 1996 en meer recentelijk de affaire rond Dexia bank. Anderzijds is deze zomer Bazel II definitief geworden. Daarmee is een lange discussie - die de bankensector in haar greep hield sinds 1999 - tot een voorlopige eindconclusie geko-

Ir. R.R. Doff is werkzaam bij Control Rabobank Groep. Daarnaast doet hij promotieonderzoek op het gebied van economic capital en RAROC.

Dr. Ir. A.H.A.J. van den Tillaart is senior auditor bij Rabobank Groep. Haar proefschrift (2003) richtte zich op de ontwikkeling van meetmethoden voor operationeel risico in het kader van Bazel II en economic capital. men. De regels die voortvloeien uit Bazel II hebben grote invloed op de risicomanagementprocessen van banken. Leenaars (2003) heeft een aanzet gegeven tot het beschrijven van het vakgebied risicomanagement bij banken. Hij schetst op overzichtelijke wijze de in de bancaire sector gebruikelijke classificatie van risico's en beschrijft per risicocategorie de meetmethoden die door de banken worden toegepast. Dit artikel gaat een stap verder en reikt een kader aan voor het samenhangend beschouwen van de bancaire risico's als onderdeel van de management control-cyclus. Het betreft hier dus interne methodes voor prestatiebeoordeling. Begrippen als Bazel II, economic capital en Risk-adjusted Return on Capital (RAROC) zijn nauw aan elkaar gerelateerd, zoals in het volgende zal blijken. Alvorens in paragrafen 3 en 4 in te gaan op de begrippen economic capital en RAROC en hun toepassingen, zal eerst de rol van solvabiliteit in de prestatiemeting worden toegelicht (paragraaf 2). Vervolgens komen het belang van kwalitatieve informatie en de tekortkomingen van het kwantitatieve begrip RAROC aan de orde.

\section{Belang van solvabiliteit voor de prestatiemeting}

In 1988 werd het eerste Bazel Akkoord van kracht, waarin werd overeengekomen dat banken uit hoofde van hun risicoprofiel een minimale hoeveelheid eigen vermogen dienden aan te houden (Basle Committee, 1988). In de bancaire sector wordt de verplichte minimale hoeveelheid eigen vermogen vaak aangeduid met de term solvabiliteit. Met de eis uit 1988 werd een tweetal doelen nagestreefd. Ten eerste verhoogde een minimale vermogenseis de stabiliteit van het bancaire stelsel, omdat meer eigen vermogen samengaat met een lagere kans op insolventie van de desbetreffende banken. De vermogenseis diende dus om depositohouders en spaarders te beschermen tegen exorbitante risicoposities van banken. Ten tweede werden met 
deze wereldwijde richtlijnen de regels voor banken geharmoniseerd, waardoor internationale verschillen kleiner werden. Het Bazels Akkoord nam op deze wijze de oneerlijke concurrentie weg. Dit moest leiden tot een 'level playing field'. Hoewel de methode voor het meten van het risicoprofiel zeer grofmazig van aard was (zie ook Leenaars, 2003, p. 346), was het indertijd een revolutionaire stap voorwaarts in het bancaire toezicht. Inmiddels is elke bank gewend geraakt aan de minimale solvabiliteitseis en is ook het marktrisico in het handelsboek onderhevig aan solvabiliteitsvereisten.

De grofmazigheid van de regels uit 1988 heeft geleid tot enkele ongewenste neveneffecten (zie ook Benink, 2005). Alle kredietverlening aan bedrijfsmatige klanten zonder hypothecair onderpand leidt in beginsel tot een solvabiliteitseis van $8 \%$ van de financiering. Dat doet onvoldoende recht aan het werkelijke risicoprofiel van de betreffende investering. Zo wordt er bijvoorbeeld geen onderscheid gemaakt tussen een groot internationaal bedrijf en een startende ITonderneming, terwijl er wel degelijk een verschil is in het risicoprofiel. Dit werkelijke risico wordt wel doorberekend in het tarief voor de betreffende financiering, terwijl er geen verschil is in het aanhouden van (dure) solvabiliteit. Op deze wijze worden banken verleid tot het aangaan van risicovolle transacties. Daarnaast is arbitrage op de Bazelse regelgeving mogelijk. Onder meer deze verschijnselen hebben ertoe geleid dat in 1999 de aanzet is gegeven tot een grootschalige herziening van het Bazels Kapitaal Akkoord, die recentelijk tot een conclusie is gekomen. Het Bazel II Akkoord, zoals het in de wandelgangen wordt genoemd, onderkent een breder spectrum aan risicogradaties en de solvabiliteitsvereisten worden ook meer op de eigen, intern ontwikkelde risicomeetmethoden van banken gebaseerd (Basel Committee, 2004). Het voert te ver om het nieuwe Bazel II Akkoord in detail te bespreken, zie hiervoor Doff (2004), DNB (2003) of Benink (2005).

\subsection{Prestatiemeting in de huidige situatie}

Het principe van solvabiliteitseisen blijft onder Bazel II overeind. Omdat de feitelijk beschikbare hoeveelheid eigen vermogen beperkt is, is solvabiliteit een schaars goed voor banken. Zij willen dit dan ook zo efficiënt mogelijk inzetten. De stuurgrootheid om dit te bereiken is de ROS, Return-on-Solvency (Bos, 1999), die een belangrijke positie inneemt binnen de management control-cyclus. De ROS wordt gedefinieerd als de winst van een bepaalde activiteit als percentage van de solvabiliteit(seis) die voor deze activiteit moet worden aangehouden (zie formule 1). De ROS kan worden bepaald voor individuele transacties, maar ook voor organisatieonderdelen of voor een bank als geheel.

$$
\text { ROS }=\frac{\text { Winst }}{\text { Solvabiliteitseis }}
$$

\subsection{Van ROS naar RAROC}

Ondanks de tekortkomingen van de oude Bazelse solvabiliteitseis werd de ROS in de jaren negentig een belangrijk stuurinstrument voor banken (Bos, 1999). Hoewel dit nooit de intentie van het Bazels Comité is geweest, werd de solvabiliteitseis op deze wijze een stuurgrootheid. Enkele vooraanstaande banken grepen de beperkingen van ROS al in een vroegtijdig stadium aan om een beter risicomeetsysteem te ontwikkelen: economic capital en daarvan afgeleid RAROC, Risk-Adjusted Return-on-Capital (Zaik, 1996). In RAROC (zie formule 2) wordt het volledige risicoprofiel van de bank meegenomen om tot een beoordeling te komen van het 'risk-adjusted' rendement. Het gaat dan niet alleen om geavanceerdere meetmethoden voor kredietrisico, maar ook om het meetbaar maken van de andere risicocategorieën. In paragraaf 3 wordt dit verder uitgewerkt.

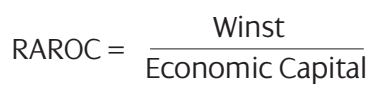

Omdat de RAROC-systematiek slechts een relatief kleine stap verder is dan Bazel II, zullen alle grote internationale banken naar verwachting RAROC implementeren nu Bazel II een feit is. In dit kader merkt Vogelaar (2002) op dat Bazel II feitelijk een tussenstap is naar Bazel III, waar naar verwachting het interne economic capital model de basis zal zijn voor het berekenen van de solvabiliteitseisen. Dat betekent dat de interne solvabiliteitseis niet slechts wordt gedreven door krediet-, markt- en operationeel risico, maar ook door rente-, landen-, verzekeringsen bedrijfsrisico.

\section{Economic capital}

De belangrijkste component van de RAROC-indicator is de noemer: het economic capital, de maatstaf voor het gelopen risico. Het economic capital is de maatstaf voor de minimale hoeveelheid vermogen die dient te worden aangehouden als buffer voor verliezen die voortvloeien uit de gelopen risico's zoals in het 
voorgaande genoemd (Matten, 2000). Merton en Perold (1993) definiëren het economic capital als een verzekeringspolis die alle verliezen uit hoofde van het risicoprofiel opvangt. Feitelijk is economic capital het interne equivalent van de solvabiliteitseis die de regelgever oplegt. De bank laat echter in het economic capital alle belangrijke karakteristieken van haar activiteiten meewegen, zoals haar eigen 'risk appetite' en alle diversificatie-effecten in de portefeuille. Dit is dus een verschil met de solvabiliteitseis (Bazel II) die is gebaseerd op een gemiddelde 'risk appetite' van alle banken en waar diversificatie slechts in beperkte mate is meegewogen.

Het economic capital wordt bepaald aan de hand van een statistische kansverdeling van verliezen ${ }^{1}$. Belangrijk is het om onderscheid te maken tussen het gemiddelde verlies door de jaren heen ('expected loss' of verwacht verlies genoemd) en tijdelijke afwijkingen van dat gemiddelde ('unexpected loss' of onverwacht verlies). Tegen verwachte verliezen dient de bank zich in te dekken via tariefopslagen in de producten, terwijl onverwachte verliezen moeten worden opgevangen door het eigen vermogen. De precieze omvang van het economic capital wordt afgeleid aan de hand van de waarschijnlijkheid en de omvang van (bijvoorbeeld krediet)verliezen. Vergelijkbaar aan Value at Risk technieken (zie Leenaars, 2003), speelt bij economic capital het betrouwbaarheidsinterval van de kansverdeling een grote rol. Het betrouwbaarheidsinterval van de bank is gerelateerd aan de 'risk appetite' van de bank en is gekoppeld aan de kredietrating (bijvoorbeeld AA) die de bank krijgt van de bekende ratinginstituten ${ }^{2}$. Er geldt dat hoe hoger de gewenste rating, des te meer economic capital moet worden aangehouden (zie figuur 1).

Figuur 1. Bepaling van het economic capital

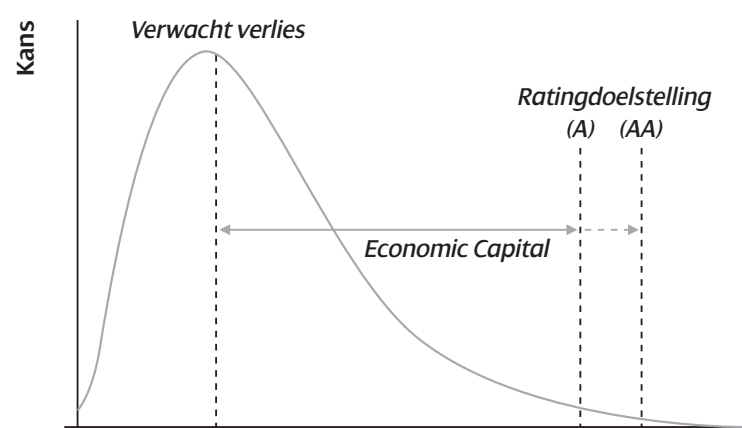

Verlies
Een tweede belangrijk element van het economic capital is de diversificatie ${ }^{3}$. Het is binnen de financiële sector gemeengoed dat risico's zich zelden gelijktijdig vertalen in verliezen. Omdat risico's elkaar deels opheffen, zal het totale risico over het algemeen lager zijn dan de som van de individuele risico's. Dat geldt derhalve ook voor het economic capital dat benodigd is voor de betreffende risico's. De vertaling van diversificatie in het economic capital is niet zo eenvoudig, omdat correlaties tussen de individuele risicocategorieën lastig zijn te berekenen. Ook de diversificatie binnen één risicocategorie is niet zo eenvoudig te berekenen. Het gaat dan bijvoorbeeld om de kansberekening wanneer twee tegenpartijen gelijktijdig niet meer aan hun verplichtingen kunnen voldoen.

Over het algemeen wordt het economic capital berekend per risicocategorie (zie tabel 1) en vervolgens opgeteld, waarbij zo mogelijk rekening wordt gehouden met diversificatie.

Tabel 1. Bepaling economic capital per risicocategorie

Risicocategorie Meetmethode ten behoeve van economic capital

Kredietrisico Inschatting verwacht en onverwacht verlies op basis van Bazel II parameters (PD, LGD, EAD)*

Marktrisico Vertaling Value at Risk naar langere periode en ander betrouwbaarheidsinterval

Renterisico Monte Carlo-simulatie, deels gebaseerd op Earnings at Risk

Liquiditeitsrisico Normaliter houden banken geen economic capital aan voor liquiditeitsrisico

Operationeel risico Combinatie van historische verliesgegevens en kwalitatieve indicatoren

Bedrijfsrisico Combinatie van volatiliteit van de baten en kostenflexibiliteit

* $P D=$ Probability of Default, $L G D=L O S S$ Given Default, EAD=Exposure at Default. Deze para meters worden gebruikt in de interne modellen voor kredietrisico, onder meer in het kader van Bazel II.

\section{Toepassingen van RAROC}

Als het economic capital eenmaal kan worden bepaald, is de stap naar RAROC een relatief eenvoudige (zie formule 2).

Economic capital is in het voorgaande gedefinieerd als de minimale hoeveelheid eigen vermogen die een 
bank zou moeten aanhouden gegeven het risicoprofiel. Het is interessant om te beoordelen in hoeverre banken hun vermogensstructuur afstemmen op de uitkomsten van de economic capital berekeningen. Uit de jaarverslagen over 2003 van drie Nederlandse grootbanken ${ }^{4}$ die informatie over hun economic capital publiceren, blijkt dat bij bepaling van de vermogensstructuur het economic capital geen doorslaggevende rol speelt. Het kernvermogen (tier 1) is beduidend hoger dan het berekende economic capital (zie figuur 2). Dat heeft verschillende oorzaken. Enerzijds zijn de data die ten grondslag liggen aan de berekeningen nog niet volledig genoeg om voldoende vertrouwen te hebben in de uitkomsten. Dat geldt voor verliesgegevens over kredietrisico, maar zeker ook voor operationeel risico. Als gevolg daarvan houden banken liever een slag om de arm en zorgen ervoor dat het aanwezige kernvermogen (aandelenkapitaal, reserves en een deel van de voorzieningen) ruim boven het minimum blijft.

Anderzijds is er op deze wijze ruimte ingebouwd om eventuele onvoorziene investeringen of acquisities te kunnen financieren. Wanneer een bank precies op het minimum zou mikken, kunnen interessante mogelijkheden verloren gaan als er op dat moment niet voldoende financieringsruimte is (het aantrekken van additioneel eigen vermogen kan bovendien in dergelijke situaties niet eenvoudig of relatief duur zijn).

Figuur 2. Kernvermogen ten opzichte van het economic capital (bron: jaarverslagen over 2003)

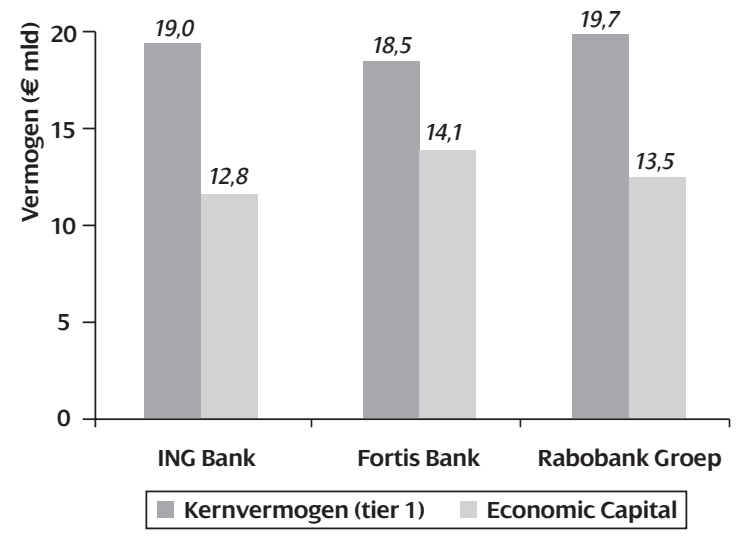

Als instrument stelt economic capital controllers en risicomanagers in staat om de raad van bestuur van de bank te ondersteunen bij belangrijke beslissingen.
Er worden over het algemeen vier toepassingen van het economic capital onderscheiden (Saita, 1999). Deze zijn:

1 economic capital als uniforme meetgrootheid voor risico;

2 economic capital als instrument om limieten vast te stellen;

3 economic capital als basis voor prestatiemeting;

4 economic capital voor de vermogensallocatie/riskbased pricing.

\section{Ad 1. Meetgrootheid}

Bij het meten van economic capital wordt voor elke risicocategorie de vertaalslag gemaakt naar de waarschijnlijkheid van verliezen (Doff, 2004). In geval van de kredietverliezen zijn de geleden kredietverliezen uit het verleden de basis voor statistische berekeningen. Bij renterisico worden de duration en Earnings-at-Risk vertaald naar het grootst mogelijke verlies van marktwaarde (binnen het gestelde betrouwbaarheidsinterval) dat in een jaar kan optreden. Omdat alle risico's op eenduidige wijze worden gemeten, zijn ze ook onderling vergelijkbaar en optelbaar gemaakt. Voor het beheersen van risico's op het niveau van de gehele bank is dat uiteraard een belangrijk gegeven. Via het economic capital kunnen risicomanagers dus met elkaar een 'gemeenschappelijke taal' spreken.

\section{Ad 2. Limieten}

Wanneer limieten worden vastgesteld op basis van economic capital kunnen bedrijfsonderdelen zelf bepalen hoe zij deze limiet invullen. Bij een gegeven limiet voor kredietrisico kan worden gekozen om goede klanten (lagere Probability of Default; PD) in te ruilen tegen slechtere klanten met meer zekerheden (combinatie van hogere PD's en lagere Loss Given Default; LGD's).

In de praktijk blijkt dat banken hun limieten voor kredietrisico momenteel nog voornamelijk vaststellen op basis van de omvang van kredieten (obligo). Banken hanteren limieten voor sectoren, landen en individuele tegenpartijen. Voor marktrisico is de Value at Risk basis voor limieten, aangevuld met stress testing en individuele risicoparameters als de delta. De limiet voor renterisico is gebaseerd op Earnings at Risk (Leenaars, 2003). De gehele limietenstructuur is een combinatie van verschillende limieten, waarbij elk een andere dimensie van het risicospectrum weergeeft. Het economic capital komt hier echter vooralsnog niet of slechts ten dele aan te pas. 
In de toekomst kan het economic capital hier echter wel een rol spelen. Zo kan de limietenstructuur voor kredietrisico worden uitgebreid met parameters als het expected loss of PD, LGD en Exposure at Default (EAD). De komst van het economic capital zal naar verwachting de bestaande limietenstructuur niet vervangen, omdat in de huidige limietenstructuur vele verschillende invalshoeken van het risicoprofiel worden belicht. Het economic capital is maar één cijfer en is derhalve niet in staat om de vele invalshoeken ineens te vervangen. Toch kan het een waardevolle aanvulling zijn. Via het economic capital worden risicocategorieën en -aspecten immers beter onderling vergelijkbaar en bovendien optelbaar. Voor de limietenstructuur zijn dat zeer prettige eigenschappen.

\section{Ad 3. Prestatiemeting}

Voor prestatiemeting worden economic capital en RAROC in grote mate toegepast. Aan de hand van RAROC kunnen bedrijfsonderdelen met een verschillend risicoprofiel op eenduidige wijze worden vergeleken. Omdat banken zich juist specialiseren in de balans tussen risico en rendement, is RAROC in deze balans van groot belang. De term Risk-Adjusted Performance Measurement (RAPM) wordt vaak gebruikt om RAROC of variaties daarop aan te duiden.

Prestatiemeting vindt plaats op het niveau van de gehele bank en de divisies van de bank, maar kan worden doorgevoerd tot aan het niveau van individuele producten en klanten. Belangrijk is de toerekening van risicocomponenten aan individuele producten. Voor de typisch bancaire risico's (zoals krediet-, markt- en renterisico) is deze toerekening relatief eenvoudig. Het krediet- en marktrisico is direct gerelateerd aan producten, terwijl voor het toerekenen van renterisico de verrekenrentesystematiek is ontwikkeld (zie Bos en Bruggink, 1996, hoofdstuk 3). De toerekening van de niet-bancaire risico's (zoals operationeel risico ${ }^{5}$ ) is vele malen problematischer, omdat deze niet zozeer zijn gerelateerd aan producten, maar voornamelijk aan activiteiten en processen. Hoewel de eenvoudige methodes van het Bazel II Akkoord de baten als verdeelsleutel voorstellen, ontwikkelen banken intern toerekeningsmethoden die zijn gebaseerd op 'key risk indicatoren' (Lawrence, 2000). Omdat deze methoden nog aan het begin van hun ontwikkeling staan, valt er op dit moment nog nauwelijks iets over te zeggen. De toerekening van bedrijfsrisico ${ }^{6}$ is overigens in een nog vroeger stadium van ontwikkeling. Hiervoor hanteren banken over het algemeen slechts vuistregels.

\section{Ad. 4 Vermogensallocatie}

Het principe van vermogensallocatie op basis van RAROC is nauw verbonden met prestatiebeoordeling. Daar waar prestatiebeoordeling achteraf plaatsvindt, gebeurt vermogensallocatie ex ante. Bedrijfsonderdelen krijgen een hoeveelheid economic capital toegewezen, bijvoorbeeld aan het begin van de budgetcyclus, waarmee zij worden geacht een vooraf afgesproken rendement te behalen. Uiteraard wordt dit rendement uitgedrukt in RAROC. Het minimale rendement dat de bedrijfsonderdelen moeten behalen, wordt vaak de 'hurdle rate' genoemd. Vermogensallocatie is daarmee een instrument geworden dat de raad van bestuur in staat stelt om doelen te stellen waarbij de risicorendementbalans ineens wordt samengevat. Gedurende de control-cyclus kan via prestatiemeting de vinger aan de pols worden gehouden.

Vermogensallocatie kan worden doorgevoerd tot elk niveau van de organisatie, zelfs tot aan individuele producten. In dat geval spreken we van 'risk-based pricing. In het tarief dat aan de klant wordt doorgerekend, is niet alleen een opslag opgenomen voor het verwachte verlies, maar ook de kosten van het economic capital worden gedeeltelijk doorberekend aan de klant. Het volledige risicoprofiel is dan verwerkt in het tarief van het desbetreffende product, hoewel ook hier de allocatie van de niet-bancaire risico's aan individuele producten of klanten lastig kan zijn.

\section{5}

\section{Kwalitatieve informatie en historische data}

Vrijwel alle grote internationale banken zijn op dit moment doende om het RAROC-concept te implementeren. Hiermee krijgen zij een zeer waardevol stuurinstrument tot hun beschikking dat de kern van hun bedrijfsvoering in ultima forma tot uitdrukking brengt: de balans tussen rendement en risico. De methoden zijn echter nog verre van perfect. Dat wordt enerzijds veroorzaakt door het tekort aan data, maar anderzijds ook door een antal conceptuele problemen.

De conceptuele problematiek die Van den Tillaart (2001) reeds aanhaalde, speelt nog steeds: operationeel risico meten op basis van statistiek gaat voorbij aan de beheersing van operationeel risico en de mogelijkheid om dit risico te beïnvloeden. Kwalitatieve maatregelen hebben een grote invloed op de waarschijnlijkheid van operationele verliezen, maar dit komt slechts zelden terug in de statistieken. Parallel daaraan bepaalt de kwaliteit van de interne kredietprocessen het moment waarop de specialisten 
bijzonder kredietbeheer bij extra risicovolle financieringen worden betrokken en de mate waarin deze specialisten erin slagen om de financiering weer 'op de rit' te krijgen. Daarmee is het proces een belangrijker voorspeller van verliezen dan de karakteristieken van de klant en de financieringsstructuur welke ten grondslag liggen aan de economic capital berekeningen. De kwaliteit van de interne processen is ook maatgevend voor rentevoorspellingen op basis waarvan verliezen in het handelsboek en de mismatchpositie van de bank kunnen worden beperkt. In dit kader merkt ook Kukler (2004, p. 19) op dat '...historische data vooral iets [zeggen] over de historische kwaliteit van de interne processen van een bank en veel minder over de toekomstige successen van risicoinschatting.'

Het blijkt niet eenvoudig om de kwalitatieve elementen die in de beheersing van de bancaire risico's een rol spelen, een plaats te geven in het kwantitatief georiënteerde economic capital begrip. De Nederlandse toezichthouder heeft met de Regeling Organisatie en Beheersing hiertoe een aanzet gegeven en ook in de tweede pijler ('supervisory review') van het Bazel II Akkoord zullen enkele kwalitatieve elementen van risicobeheersing hun weerslag moeten vinden. Het feit dat de praktische uitwerking van de tweede pijler nog niet zo ver is gevorderd, geeft al aan dat de nadruk bij de banken en de toezichthouder op het kwantitatieve vlak ligt. Dat geldt zeker ook voor het economic capital concept. Hoewel economic capital het vakgebied risicomanagement bij banken heeft gestimuleerd zich in de kwantitatief/statistische richting te ontwikkelen, blijft kwalitatief risicomanagement de belangrijk(st)e determinant van verliezen (Tschoegl, 2000).

De problematiek van historische data komt tot uitdrukking in drie deelgebieden. Ten eerste zijn historische data schaars waar het gaat om extreme verliezen. Het schatten van de 'dikke staart' van de frequentieverdelingen is dan ook schier onmogelijk (Pézier, 2003). Ten tweede stelt de homogeniteit van datasets de banken voor uitdagingen. Ten slotte is het bepalen van de diversificatie door de dataschaarste bijna onmogelijk.

\section{Extreme verliezen}

Eén dataprobleem bij het schatten van extreme verliezen is dat data snel verouderen en daardoor niet meer bruikbaar zijn. Vaak is het economic capital gebaseerd op een kans van circa 1 op 2.000 en zelfs kleiner. Deze kans wordt gebruikt om de 'risk appetite' van de bank uit te drukken en is gerelateerd aan de kredietrating van de bank. Om deze kans statistisch significant te schatten, zijn zeer veel data nodig, die echter niet voorhanden zijn. Het is belangrijk dat banken deze dataproblematiek oplossen, omdat het economic capital (en derhalve ook RAROC) zich juist richt op de extreme, weinig voorkomende verliezen.

\section{Voorspellende modellen}

De voorspellende modellen voor kredietrisico worden steeds specifieker toegespitst op individuele productsoorten of klantgroepen. Grote bedrijfsklanten worden onderscheiden van middelgrote en soms wordt daarbinnen nog onderscheid gemaakt naar productsoorten. Dat heeft tot gevolg dat het aantal datapunten binnen de modellen kleiner wordt en er te weinig datapunten voor elk individueel model zijn om statistische significantie te bereiken. Het is derhalve een afweging tussen voldoende omvang en voldoende homogeniteit in de datasets. Om dit probleem op te lossen wordt vaak gebruikgemaakt van zogenaamde 'expert judgement' om zonder voldoende data toch een bruikbaar model te ontwikkelen. Voor operationeel risico heeft dit in 2001 zelfs geleid tot aanpassing van de voorstellen van Bazel II, waardoor kwalitatieve modellen ('scorecards') werden toegestaan $^{7}$ (Van den Tillaart, 2003). Tijdens het ontwikkelen van de risicomodellen geeft gebruik van 'expert judgement' weliswaar verlichting, maar tijdens de validatie van het model komt dezelfde problematiek weer terug. Zolang de voorspellende waarde van het expert judgement model niet statistisch is aangetoond, wordt het model niet geaccepteerd binnen de huidige visie op risicomanagement. Het Bazels Comité is van mening dat 'estimates must be grounded in historical experience and empirical evidence, and not based purely on subjective and judgemental considerations' (Basel Committee, 2004, artikel 449). Ook hier speelt dat Bazel II en de economic capital methode tekortschieten bij het gebruik van waardevolle kwalitatieve informatie.

\section{Diversificatie}

Ten slotte is voor het bepalen van de diversificatie een grote hoeveelheid data benodigd. Deze data zijn momenteel nog niet in voldoende mate voorhanden bij banken. De diversificatie is één van de belangrijkste componenten van de economic capital berekeningen. Daarom is het van groot belang dat deze component op adequate wijze wordt bepaald, maar juist hiervoor zijn de meeste historische gegevens nodig. Aan de belangrijkste component van het economic capital zijn de banken dus nog onvoldoende 
toegekomen. Ter compensatie reiken adviesbureaus als Mercer Oliver Wyman - die bij vrijwel elke grootbank actief zijn - benchmarks aan. Deze gaan juist voorbij aan de specifieke karakteristiek van de bank, die in bepaalde sectoren beter of minder goed gediversificeerd is dan het gemiddelde van de benchmark. Het zal nog enige jaren duren alvorens voldoende data zijn verzameld om de diversificatie adequaat te berekenen. Tegen die tijd zal het voor de banken een uitdaging zijn om relevantie van de wellicht verouderde data adequaat te beoordelen.

\section{Ten slotte}

In de eerste paragrafen van dit artikel is de RAROCmethodiek beschreven en aan de orde gekomen welke plaats RAROC kan innemen in de bancaire besturing. Aan de hand van economic capital en RAROC kunnen banken hun risico's op uniforme wijze inzichtelijk maken. De methode biedt banken een zeer waardevol instrument om de bedrijfsactiviteiten te beoordelen aan de hand van het risicorendementvraagstuk en biedt tal van toepassingen die het management control-instrument verrijken (zoals uiteengezet in paragraaf 4). Via vermogensallocatie is RAROC een pro-actief stuurinstrument voor de bank. Slechts enkele vooraanstaande internationale banken zijn al zo ver dat ze RAROC volledig kunnen opnemen in het management control-instrumentarium. Het zal zeker nog een aantal jaren duren voordat een grotere groep banken zo ver is. RAROC is echter een grote stap voorwaarts in de besturing van banken en zal de komende jaren steeds belangrijker worden, dat moge duidelijk zijn.

Een belangrijke voorwaarde is echter dat bij de interpretatie van RAROC-cijfers 'gezond boerenverstand' een belangrijke rol blijft spelen. Enerzijds zijn er op cruciale onderdelen nog hiaten in de data. Als gevolg hiervan moeten controllers en risicomanagers bij het analyseren van de cijfers vooral kijken naar de trends en de verhoudingen tussen bedrijfsonderdelen. Dit kan al waardevolle informatie geven ter ondersteuning van beslissingen.

Anderzijds moet de interpretatie van RAROC-cijfers worden angevuld met kwalitatieve informatie over de risicobeheersingprocessen binnen de bank. In de toekomst zal binnen het vakgebied risicomanagement dan ook een nieuwe zoektocht moeten plaatsvinden naar een methodiek waarbij kwalitatieve informatie een gestructureerde plaats krijgt in de besluitvorming, naast de zoektocht naar dataverfijning en verfijning van de statistische technieken. Men zou moeten mikken op een mix van twee elementen (kwantitatief en kwalitatief). Onzes inziens is juist hier de grootste verbetering van de RAROCmethodiek te behalen. Hier ligt een belangrijke taak voor controllers en risicomanagers van de bank, die de raad van bestuur ondersteunen in beslissingen op basis van RAROC.

Dit artikel is geen betoog tegen de RAROCmethodiek als zodanig, integendeel. Hoewel RAROC een nuttig instrument is voor banken, willen we graag een kritische noot plaatsen bij de kwantitatieve oriëntatie die de methodiek momenteel heeft. Het is dan ook een illusie om bij de besturing van de bank alleen te kunnen varen op de RAROC-uitkomsten. Parallel aan de discussie rondom de limietenstructuur kan het control-instrumentarium niet bestaan uit slechts één metertje. De controller van de bank dient te beschikken over meerdere metertjes op zijn dashboard, waarbij de RAROC een belangrijke, doch niet de enige plaats mag innemen.

\section{Literatuur}

Basle Committee on Banking Supervision, (1988), International Convergence of Capital Measurement and Capital Standards, Bank for International Settlements.

Basel Committee on Banking Supervision, (2004), International Convergence of Capital Measurement Standards: A Revised Framework, Bank for International Settlements.

Benink, H., (2005), Bazel II: enkele actuele issues, in: Maandblad voor Accountancy en Bedrijfseconomie, jg. 79, nr. 1/2, januari/februari (nog te verschijnen).

Bos, J.J., (1999), Prestatiebeoordeling bij banken: van mixed model naar fair value, NIBE.

Bos, J.J. en A. Bruggink, (1996), Management control bij banken, NIBE.

Culp, C.L., (2000), RAROC Revisited: ex ante vs. ex post RAROC, in: Journal of Lending and Credit Risk Management, vol. 82, no. 6, March, pp. 50-57.

DNB, (2003), Bazel II: implicaties voor Nederland, in: DNB kwartaalbericht, september 2003, pp. 53-61.

Doff, R.R., (2004), Economic capital en risicobeheer bij banken, NIBE-SVV.

Kukler, A.. (2004), Bazel II: data of wijsheid?, in: Bank- en Effectenbedrijf, april, pp. 16-19.

Leenaars, H., (2003), Risicomanagement van banken, in: Maandblad voor Accountancy en Bedrijfseconomie, jg. 77, nr. 7/8, juli/augustus, pp. 340-347.

Lawrence, M., (2000), Marking the Cards at ANZ, in: Risk, Operational Risk Special Report, November, pp. s8-s12.

Matten, C., (2000), Managing Bank Capital, Wiley Press, second edition. Merton, R.C. en A.F. Perold, (1993), Theory of Risk Capital in Financial Firms, in: Journal of Applied Corporate Finance, vol. 5, no. 3, pp. 16-32. Pézier, J., (2003), A constructive review of the Basel proposals on operational risk, in: C. Alexander (ed.), (2003), Operational risk: 
regulation, analysis and management, Prentice Hall.

Operational Risk, (2001), Advanced Measurement Approaches, in: Operational Risk, October 2001, p. 14.

Saita, F., (1999), Allocation of Risk Capital in Financial Institutions, in: Financial Management, vol. 28, no. 3, pp. 95-111.

Schroeck, G., (2002), Risk management and value creation in financial institutions, Wiley, 2002.

Tillaart, A.H.A.J. van den, (2001), Operationeel risico meten, een kritische beschouwing, in: Maandblad voor Accountancy en Bedrifseconomie, jg. 75 , nr. 11, november, pp. 458-462.

Tillaart, A.H.A.J. van den, (2003), Controlling Operational Risk: Concepts and Practices, NIBE-SVV.

Tschoegl, A.E., (2000), The key to risk management: management, in: M. Frenkel et. al., (2000), Risk Management: Challenge and Opportunity, Springer Verlag.

Vogelaar, N., (2002), Bazel II als opmaat voor Bazel III, in: Bank-en Effectenbedrijf, maart, pp. 24-26.

Zaik, E., J. Walter, G. Kelling en C. James, (1996), RAROC at Bank of America: from theory to practice, in: Journal of Applied Corporate Finance, vol. 9, no. 2, Summer 1996, pp. 83-93.

\section{Noten}

1 Het voert te ver om de statistische meetmethoden in detail te bespreken. Hiervoor verwijzen wij naar Doff (2004) en Leenaars (2003).

2 Rating instituten als Moody's en Standard \& Poor's vormen een oordeel van de kredietwaardigheid van bedrijven en publiceren dit als ondersteuning voor investeringsbeslissingen van beleggers. Het oordeel wordt uitgedrukt in lettercodes waarbij AAA de hoogste rating is en CCC de laagste.

3 In verband met diversificatie worden verschillende vormen van economic capital onderscheiden: stand-alone economic capital, gediversificeerd economic capital en marginaal economic capital. Het voert hier te ver om daarop dieper in te gaan. Meer informatie is te vinden in Doff, 2004, p. 139

4 ING bank, Fortis Groep en Rabobank Groep publiceerden over het verslagjaar 2003 informatie over economic capital en RAROC. ABN Amro doet dit niet, maar hanteert intern wel een economic capital methode.

5 Operationeel risico wordt gedefinieerd als 'the risk of loss resulting from inadequate or failed internal processes, people and systems or from external events' (Basel Committee, 2004, artikel 644). Dat dit risico moet worden gemeten is relatief nieuw in de bancaire omgeving.

6 Bedrijfsrisico ('business risk') is het risico van veranderingen in de concurrentieomgeving en de mate waarop de bank hierop kan inspelen. Te denken valt aan internetbankieren, veranderende regelgeving, et cetera. In de economic capital methoden van alle banken wordt bedrijfsrisico opgenomen, vaak zijn de meetmethoden echter nog zeer grofmazig. Zie ook Doff, 2004, p. 86.

7 Van den Tillaart (2003) beschrijft de achtergronden rondom deze revolutie uitgebreid in hoofdstuk 3 . 